\title{
A Review of Operational Surgery in Ent and Cervical-Facial Tumours - Oral Cavity and Pharynx
}

\author{
CONSTANTIN MIHAI ${ }^{1}$, DRAGOS OCTAVIAN PALADE ${ }^{1 *}$, CRISTIAN BUDACU1*, IULIU FULGA ${ }^{2}$, MIHAELA GABRIELA LUCA ${ }^{3 *}$, \\ ANA GABRIELA SENI ${ }^{3}$, ALEXANDRU GRIGOROVICI ${ }^{1}$, LAURIAN LUCIAN FRANCU ${ }^{1}$, IOAN SARBU ${ }^{4}$ \\ ${ }^{1}$ Grigore T. Popa University of Medicine and Pharmacy, 16 Universitatii Str., 700115, Iasi, Romania \\ 2Dunarea de Jos University of Galati, Faculty of Medicine and Pharmacy, 47 Domneasaca Str., 800008,Galati, Romania. \\ 3University of Medicine and Pharmacy, 38 Gheorghe Marinescu Str., 54139, Targu Mures, Romania \\ ${ }^{4}$ Carol Davila University of Medicine and Pharmacy, 8 Eroii Sanitari, 050474,Bucuresti.
}

It is extremely difficult to synthesize in a paper the extremely wide diversity of the issues related to such a vast chapter such as the tumours in the ENT area and the cervical-facial region. The review analyses the variety of benign and malignant types of tumours, presenting various types of tumours on anatomical organs or regions, insisting with more extensive data from the literature on less frequent tumours or involving more distinct therapies, perhaps leading to a lack of balance and uniformity. Tumours are defined as excessive proliferation of abnormal cells that resemble more or less the tissue in which they develop and end up by acquiring biological autonomy. The study performed presents a batch of 425 patients diagnosed with benign tumours - 306 cases (72.0\%) and 119 cases with ENT and cervical-facial malignanttumours thathad extensions to the surrounding organs and metastatic adenopathies, admitted and treated at the Clinical Maxillofacial Surgery Clinic of the County Clinical Hospital between 1.01.2015 - 31.12.2018. The entire cancerous lesion is surgically removed together with a small surrounding healthy tissue area to ensure that all malignant cells have been removed. The purpose of the surgery is to remove all affected tissues without compromising the integrity of the structures in the other areas of the oral cavity. Tumours develop from the oropharynx: the tonsils, the base of the tongue, the soft palate, the pharyngeal posterior wall. Most often, the tumour affects the tongue floor, the mucous of the mouth and the tonsils.

Keywords: ENT tumours, cervical-facial tumours, oral cavity, pharynx, benign tumours, malignant tumours, surgery

The oral cavity begins through the vestibule of the mouth, represented by a slot-shaped space between the inner face of the cheeks and the lips on the one hand and the external face of the teeth and alveolar processes of the jaws on the other. At the level of the second superior premolar, on the genian mucosa there is the orifice of Stenon's canal [1,2].

The actual oral cavity is limited: laterally and anteriorly to the inner face of the teeth, down from the muscles of the tongue: hyoglossus, styloglossus, genioglossus and diaphragm of the mouth (milo-hyoidian muscle), above the palatine vault, composed of the hard palate in the anterior portion and the soft palate in the posterior one $[3,4]$.

The lining of the hard palate is represented by mucous membranes, submucous glands, periosteum and bone (palatal apophysis of the upper jaw, palatine bones). In the posterior region of the hard palate, that is to say in the horizontal region of the palatine bones, on the sides there are the big palatine holes through which the palatine artery coming from the pterygopalatine canal enters (branch of the internal maxillary artery) and the palatal nerve (from the upper jaw nerve), which go to this region $[5,6]$.

The homonym arteries and veins are located subperiosticallyalong the edges of the palate near alveolar apophyses. The lymphatic vessels are directed towards the palatal tonsils and further to the deepest superior cervical lymph nodes.

The soft palate consists of two mucous layers, among which the following muscles occur: palatal-thick, palatalpharyngeal, the palatine veil lifting muscle (internal peristaphyline) and others.
Arterial vascularisation is mainly performed by the branches of the small palatine arteries (from the descending palatine artery), which come out from the homonymous orifices in the region of the horizontal part of the palatine bones. The region is innervated by the branches of the small palatine nerve and by the fibres coming from the otic ganglion. The lymph flows following the same paths as for the hard palate $[7,8]$.

The back segment of the soft palate, in the form of the anterior and posterior pillars, and the lutea, hangs down and forms with the tongue basis the isthmus of the pharynx, which divides the oral cavity from the pharynx. In the niche between the palatine vale pillars there are the palatine tonsils, which together with the pharyngeal and lingual tonsils form a lymph tissue ring in the isthmus region $[9,10]$

The tongue, covered by the mucosa, is located on the floor of the mouth. The sublingual region is discovered after the tongue rises up. From the lower face of the tongue there is a median fold, the lingual frenum, which sometimes may be short, and we have to cut it in case of children in order to suppress speech defects. Next to the posterior-inferior end of the lingual frenum, on the lateral sides there are the nipples, on which the channels of the sublingual and sub-maxillary salivary glands open through a common orifice[11].

The pharynx appears in the form of an anterior opened muscular tube in the oral and nasal cavity and continues downward with the esophagus.

*email:drpalade@gmail.com; cristian.budacu@umfiasi.ro; lucamihaela@yahoo.com 
At the level of pharynx, we distinguish the following segments: upper, nasal or nasopharyngeal, opening into the nasal cavity through the cons; on its lateral walls there are the orifices of Eustache's tubes, which enable the communication of the pharyngeal cavity with that of the middle ear, the middle, oral, stretched between the palatine veil and the epiglotte, previously it communicates through the pharynx isthmus with the oral cavity, the lower laryngeal area, located behind the larynx up to the place of passage of the pharynx into the esophagus. The upper wall of the pharynx, or the pharyngeal vault, is fixed to the external surface of the base of the skull along the edges of the gutural fossa. The posterior wall is sutured on the anterior face of the bodies of the 6 cervical vertebrae, being separated from these by the prevertebral fascia $[12,13]$.

The posterior-lateral wall of the pharynx consists of the mucous, the muscular layer and the pharyngeal fascia that cover it externally. There is a layer of cellular tissue (retropharyngeal space) between the pharynx posterior wall and the prevertebral fascia in which there are placed the retropharyngeal lymph nodes, collecting the lymph from the palatal tonsils, the posterior area of the oral and nasal cavities. Through these lymphatic pathways, the microbes can penetrate into the retropharyngeal space, leading to the formation of a retropharyngeal abscess [14, 15].

The retropharyngeal space communicates with the cellulosic tissue on the lateral sides of the pharynx (peripheral space); downwardly, it continues along the esophagus, constituting the pathway of fusion of suppurative processes. Arterial vascularization of the pharynx is provided by arteries: ascending pharyngeal (from the outer carotid artery) and upper thyroid.

The veins form a developed plexus in the wall of the pharynx, from which the blood refills in the internal jugular vein system. The innervation is made by the branches of the glossopharyngeal and pneumogastric nerves.

The mentonier region corresponds to the horizontal line that runs along the suprametonier fold, and downward with the lower edge of the mandible. Laterally it corresponds to the vertical lines taken from the lip commissures [16-18].

The skin is rich in sebaceous and bladder glands (in men). The subcutaneous cellular tissue is made of mimicking muscles, vessels and nerves.

The vascularization is provided by the branches of the arterial artery (from the lower alveolar artery), which penetrates the region through the mentonier hole, as well as by the submentonier arteries and the crown of the lower lip (from the external maxillary artery). The innervation is provided by the metonier and facial nerves [19-21].

\section{Benign tumours}

The main groups of benign tumours that may develop in the oral cavity are formed by cysts, epithelial tumours, conjunctival tumours, glandular tumours and benign reticular tumours.

The group of cysts include besides congenital formations (dermoid) those of retention and grenouillette formations.

Benign epithelial tumours are represented by papillomas and adenomas developed from minor salivary glands.

Conjunctive tumours are represented by epulis, fibroids, lipomas, neurinomas, leyomiomas, myomas, rhabdomyomas, myoblastomas (Abrikosov tumour), angioendothelioma, angiopericytoma (Stout), hemolymphangiomas.

Among the glandular tumours besides those developed from the minor salivary glands, which are mostly mixed tumours, we describe the lingual thyroids encountered mainly in females and which can represent the only thyroid tissue, the thyroid gland being absent.

Benign pharyngeal tumours are dominated by nasopharyngeal fibroma, a benign tumour well known by ENT specialists the postoperative prognosis of which has improved significantly over the past decades due to advanced anaesthesia techniques, the widening of the indication of the operative act irrespective of tumour size, the use of vascular embolization, hormone therapy and radiotherapy. Rarely encountered are branchiogenic and retention cysts, which can develop into rhinopharynx from Rathke's bag, hamartroma (teratomas with a didermic structure) can pose special, breathing problems in the newborn, so that ablation will impose urgency [22, 23].

Papillomas, lipomas, adenoma, and myomas when they appear do not usually pose special problems of surgical ablation.

Parapharyngeal tumours developed in perinpharyngeal spaces are clinically easy to diagnose, but they can raise difficulties in their surgical resolution. These are represented by schwannoma or ganglioneuroma developed from cranial or sympathetic nerves, mixed parotid tumours, developed from the pharyngeal prolongation of this gland, vascular tumours or adenopathy $[24,25]$.

Precancerous states of the oral cavity and pharynx are represented by leucoplasias, lichen planus, exophytic or papillomatous keratosis (Gerard-Marchans and Y.Cachin) requiring rigorous quarterly controls to capture malignancy and Gougerot-Sjogren's disease currently considered autoimmune disease during whose development oropharyngeal changes such as the epitheliomatous degeneration occur and the evolution of non-Hodgkin's liposomes are important for the ENT practitioner and dentist.

Malignant tumours - two types of malignant tumours develop in the oral cavity and pharynx: epithelial and lymphoid.

Malignant epithelial tumours of the cavum account for $70 \%$ of the total of this localization, the remainder being mainly malignant lymphomas (1/3) and a very small amount of lymphoepitheliomas, adenocarcinoma, cylindroma, plasmacytoma, chordoma.

Rhinopharyngeal malignant lymphomas should not be regarded as a strictly localized organ or locoregional disease (in case of presence and lateral cervical adenopathy) but as a disease of the entire reticuloendothelial system in which the affection of the organs rich in such tissue (liver, spleen, lymph nodes) can be quite frequently encountered so that a clinical and laboratory balance is required from the onset of the disease $[26,27]$.

Transcutaneous telecobalt therapy performed on both the primary tumour and on the lymph nodes is firstly recommended, with the mention that in the presence of an epithelial tumour it is possible to complete the treatment on lymph node areas with a lymph node resection when the irradiation therapy did not have the result expected (residual adenopathies).

Chemotherapy is the obligatory treatment for malignant lymphoma, its place being paramount in case of the presence of histologically unfavourable lymphomas and adjuvant of the radiation therapy for lymphomas with favourable histology [28, 29].

In malignant tumours of the oral cavity and oropharynx a special place is occupied by the cancer of the tongue, tonsil, palatine veil, the upper palate and gingival region, of 
which for the surgeon that of the tonsil, of the palatine veil and of the base of the tongue is important for the therapeutic solution.

Mobile tongue and oral floor cancer represent $20 \%$ of all upper aerodigestive locations, with a much more favourable prognosis than baseline (fixed) tongue cancer.

The advanced techniques of surgical therapy, local and transcutaneous irradiation, chemotherapy, especially combined, made the average survival rate of over 5 years in case of the mobile tongue cancer to be of $40 \%$ and of that of the oral floor to be of over $25 \%$.

Base tongue cancer has a much worse prognosis than the mobile portion. The treatment of choice is transcutaneous irradiation, its results being constantly better in the vegetative forms compared to the ulcerative forms. The surgical treatment consisting of total subglosolaringectomy results in relatively favourable results in a very limited number of cases.

Malignant tonsil tumours are made up to a proportion of $85 \%-90 \%$ of the cases of epitheliomas, the rest being represented by malignant lymphomas. Of all upper aerodigestive tumours, we find them in a percentage of $15 \%$.

In epithelial tumours in cases where the tumour has not invaded the surrounding tissues, prognosis is all the more favourable as the lesion is located on the upper pole of the tonsil.

Due to the ulcerative character, the possibility of superinfection, concomitant adenopathies or even in-depth adherence, the experience of the surgeon combined with that of the oncologistcan select situations in which doctors can perform from simple tonsillitis extended to transmaxillary bucopharyngectomies with extensive resections, concomitant lymph nodes resections and simultaneous or subsequent plastic surgeries.

If tonsil malignant lymphoma is present, as in the case of rhinopharyngeal localization after an examination which should include the hepatic and splenic scintigraphy is made, radiation therapy and chemotherapy will be applied.

Malignant tumours of the palate can develop in the apalatine vault from the level of the veil, the latter being of importance to surgeons.

The tumours of the palate are represented in the vast majority of cases by epitheliomas, and to a lesser extent by tumours of the salivary glands. Their therapy consists mainly of transcutaneous irradiation. The indications of surgical treatment of exertion are quite limited.

The vail tumours have an increased histological diversity, with epithelial tumours in the first place, but there may be malignant hematosarcomas, mesenchymal sarcomas, mixed tumours or cylindrous tumours. The therapeutic attitude depends on the nature and size of the tumour: radiotherapy, radiosurgery or surgery. They have a severe prognosis due to lymphatic connection and dissemination and extension in the neighbouring areas.

Malignant tumours of the gums are rare, receiving surgical resection treatment if they are found at an early stage. In more advanced stages they are treated by radiotherapy of the primary tumour with the indication that a subsequent osteonecrosis process may occur, followed if appropriate by ganglionic resection of the satellite metastatic adenopathies.
The malignanttumours of the hypopharynx, represented in $80-90 \%$ of cases by the localization at the level of the pyriform sinuses, have a sever prognostic because they are clinically silent, as the limited forms with higher therapeutic possibilities can only be detected in a percentage of $20-25 \%$ of cases; even in cases where surgical treatment can be applied, it will be mandatory physiotherapy. Due to the special lymphophya of hypopharynx cancers, the lymph node time is obligatory so that even when the adenopathies are not perceived at the clinical examination, a (prophylactic) ganglion resection will be performed by principle [30].

The conservative surgery of the hypopharynx basically represented by the partial lateral pharyngectomy (Trotter), and vertical hemi-laryngo-pharyngectomy and super glottic hemi-larynx-pharyngectomy has very limited indications. Some cases of total laryngectomies are accompanied by partial pharyngectomies. Also, a total circular pharyngeal- ringectomy can be applied; we have practiced it in some cases but withoutobtaining favourable results in time, so we have given up this type of intervention.

Telecobaltotherapy and ultra-penetrating radiotherapy (linear electron accelerator, betatron, high energy electrons) remain the basic therapy of hypopharynx cancers, giving an average survival of about 3 years.

In rare cases which benefit from combine treatment of radio-surgery, survival is of 5 years in $40 \%$ of patients with limited tumours and $20 \%$ in those with tumours less extended but accompanied by adenopathy.

\section{Experimental part}

\section{Material and method}

The study performed presents a group of 425 patients diagnosed with benign tumours - 306 cases $(72.0 \%)$ and 119 cases with ENT and cervical-facial malignant tumours which had extensions to the surrounding organs and metastatic adenopathies, admitted and treated at The Maxillofacial Surgery Clinic of the County Clinical Hospital during 1.01.2015 - 31.12.2018.

\section{Results and discussions}

The cancer of the oral cavity describes a class of cancers that develop in the mouth region. It most often occurs at the level of the tongue, lips or lower oral region, but may also appear at the level of the cheeks (mouth mucosa), gums, mouth palate (hard palate and soft palate), tonsils or salivary glands; it can also develop at the level of the oropharynx, which is part of the neck area.

Oral cavity cancers are part of the ENT malignant tumours group. It may appear at any component of its structure - mobile tongue, mouth floor, retromolar triangle (behind the last molar teeth in the lower arch), hard palate, internal cheek face, lips, mouth vestibule or alveolar margin. Salivary glands, although opening into the oral cavity, cannot be included in this category, and this is due to histological features.

Oral cancers occur when cells at this level develop mutations at the DNA level. These mutations allow cancer cells to develop and divide uncontrollably. Accumulation of abnormal cells in the mouth may form tumours. Over time, these can spread to the depth of tissue or in other regions of the head, neck or other areas of the body.

Oral cancers are usually formed from flat thin cells that cover the lips and the inside of the mouth.

Some inborn genetic mutations that produce different syndromes in the body increase the risk of oral cancers. These are: Fanconi anemia-it is a blood disorder caused by inborn abnormalities; problems can begin at an early age 
and can lead to leukemia or aplastic anemia; congenital dyskeratosis - it is a generic syndrome that can cause aplastic anemia and increases the risk of oral cancers in early ages.

The malignant tumours of the hypopharynx represent $0.6-1 \%$ of the total malignant tumours and $7-10 \%$ of the ENT area malignant tumours.

Human Papillomavirus (HPV serotypes 16-18) infection. Certain strains are risk factors and etiologic agents for tumours with squamous histology of the oral cavity.

Human Papilloma Virus (HPV) is now accepted as a risk factor in the development of squamous cancers of the oropharynx (especially in lingual, tonsil and tongue bases cancers).

Molecular studies in oral cavity and pharyngeal tumours have revealed that the epidermal growth factor receptor (EGFR) gene amplification with EGFR overexpression are common among cancer patients and are associated with poor prognosis.

Early molecular studies of ENT area carcinoma also revealed that mutations, loss of heterozygotism and methylation of the CDKN2A locus are very common and appear early in the development of ENT area carcinoma. Mutations and overexpression of p53 have also been identified in early trials of the ENT area carcinoma. Cyclin D1 amplification and overexpression have been identified as an important biomarker that is associated with the results and response to treatment.

Tumoral dissemination is carried out contiguously, lymphatically and rarely in a haematogenic manner. The extension direction for the hypopharyngeal cancer is determined by the presence of adherence areas that are a hindrance to tumour growth. The most important route of tumour dissemination is the lymphatic one. At the time of invasion of a group of cervical lymph nodes, which makes it clinically evident, it is possible that cancer cells have included other lymph nodes that are not yet palpable by contiguity, and their non-removal leads to evolution and clinical stages with a more reserved prognosis. Remote metastasis of the hypopharyngeal neoplasm can occur in the liver, lungs.

Swallowing disorders may be the first sign of a tumour pathology in the upper aerodigestive area. Sometimes an insidious screening is required in the search for an occult primitive tumour, making this a complex and difficult approach. In cervical and facial tumour pathology, dysphagia occurs in $14-18 \%$ of the cases prior to any treatment. In turn, excisional surgery may cause disorders of the swallowing process by ablation or damage to the anatomical function of the process. Cervical surgery, even for the ablation of benign tumours, can damage the cranial nerves involved in swallowing, with serious consequences on the quality of life of the patient, and reconstructive surgery is aimed at restoring the anatomical substrate rather than the functional one.

Despite the consciousness of EGFR overexpression and its potential value as a target for therapy, it is still impossible to predict which cancer in the ENT area is responding or not to this therapy.

Tumour Removal Surgery - removes the tumour or surrounding bone tissue to remove any traces of cancer cells; to remove cancer spread across the neck region - if cancer cells spread to the lymph nodes in the neck region or if there is a high risk that this may happen, based on the size of the cancer, the surgeon will recommend a procedure for removing cancerous lymph nodes and the tissue of the neck region; reconstruction surgery - after surgery destined to remove the cancer, the doctor will recommend reconstructive surgery to rehabilitate the oral cavity to regain the ability to talk and eat. Grafts of skin, muscle or bone or from other regions for the reconstruction of the oral cavity are transplanted. Dental implants can be used to replace natural teeth [31, 32].

Radiotherapy uses high-energy beams like X-rays or protons to kill cancer cells. It can be individual treatment for early cancers, or in combination with other treatments such as surgery or chemotherapy. Combination treatments increase effectiveness but also the risk of adverse effects.

Chemotherapy is a treatment that uses chemical compounds to destroy cancer cells. It can be administered individually or in combination with drugs or other treatments. Can increase radiotherapy efficiency. Side effects depend on the medicine used [33].

Target therapy treats cancer by altering the specific aspects of cancer cells that fuel the tumour. Cetuximab is an approved product for treating cancers in the mouth and throat region in certain situations. It can be used in combination with chemotherapy or radiotherapy.

\section{Conclusions}

The form of cancer grow th can be exophytic (growth in the oral cavity or on the surface of the lips) and infiltrative (the visible tumour component, clearly "spread" on the surface of the body, the change in colour and its structure, in more aggressive tumours) they may be mixed and infiltrative and ulcerative cancer.

A characteristic property of the cavity and pharynx oral cancer is frequently lymphogenous metastases (in nearby lymph nodes), sometimes on both sides. In this case, lymph nodes are affected in stages: first, metastasis occurs in the chin and submandibular nodes, then to the neck, and ultimately the last barrier is deep cervical and supraclavicular nodes.

No alternative or complementary treatment can treat oral cancer but can help reduce adverse effects of the disease or treatment; physical activity, massage therapy, relaxation techniques or acupuncture are also recommended.

\section{References}

1.ADELSTEIN DJ . Oropharyngeal cancer: the role of chemotherapy. Curr Treat Options Oncol. 2003; 4 (1): 3-13.

2.AMEN SIBTAIN, ANDREW MORGAN, NIALL MACDOUGALL: Physics for Clinical Oncology (Radiotherapy in Practice), Oxford Univ Press, 2012.

3.SCUTARIU MM, HINGANU D, MACOVEI G, HINGANU VM. Anatomical and functional organization of the muscular aponevrotic cervicofacial system. Romanian J ournal of Oral Rehabilitation ,Vol.10, No. 4, Octomber-December 2018, pg. 186 - 192, ISSN 2066 - 7000

4.BERNIER J, DOMENGE C, OZSAHIN M, MATUSZEW SKA K, LEFEBVRE JL, GREINER RH, GIRALT J, MAINGON P, ROLLAND F, BOLLA M, COGNETTI F, BOURHIS J, KIRKPATRICK A, VAN GLABBEKE M. Postoperative irradiation with or without concomitant chemotherapy for locally advanced head and neck cancer. N Engl J Med. 2004; 350 (19): 1945-1952.

5.MIHAELA MONICA SCUTARIU, IORDANIS SALAMASTRAKIS, CRISTINEL IONEL STAN, ALIN HORATIU NEDELCU, LIVIU CIPRIAN GAVRIL, CLAUDIA FLORIDA COSTEA, ANA MARIA DUMITRESCU, ANCA SAVA, ELENA SARPE. Histopathological Consequences of Hyperzincemia on Rat Teeth. Experimental Study. Romanian J ournal of Morphology and Embryology, vol.57, nr.3, decembrie 2016, pg. 1057 -1061. ISSN 1220-0522

6.BRIEGER J, JACOB R, RIAZIMAND HS, ESSIG E, HEINRICH UR, BITTINGER F, MANN WJ. Chromosomal aberrations in premalignant and malignant squamous epithelium. Cancer Genet Cytogenet. 2003; 144 (2): 148-155. 
7.CHANG AE, LI Q, JIANG G, TEKNOS TN, CHEPEHA DB, BRADFORD $C R$. Generation of vaccineprimed lymphocytes for the treatment of head and neck cancer. Head Neck. 2003; 25 (3): 198- 209.

8.HINGANU D, SCUTARIU MM, HINGANU MV. The existence of labial SMAS - Anatomical, imaging and histological study. ANNALS OF ANATOMY-ANATOMISCHER ANZEIGER, 2018, 218: 271-275.

9.DAVID S. CHANG, FOSTER D. LASLEY, INDRA J. DAS, MARC S. MENDONCA, JOSEPH R. DYNLACHT:Basic Radiotherapy Physics and Biology, Springer,2014.

10.ESPITALIER F. Etal. International consensus (ICON) on assessment of oropharyngeal dysphagia / European Annals of Otorhinolaryngology, Head and Neck Diseases. 2018; 135, S17-S21.

11.FORASTIERE A, KOCH W, TROTTI A, SIDRANSKY D. Head and neck cancer. N Engl J Med. 2001; 345(26): 1890-1900.

12.HANSEN EK, ROACH M III (eds): Handbook of evidence based radiation oncoloy. Springer, 2007.4 Nagy $N$ (ed): Principii de cancerologie geneala. Ed. Medicala Universitara Iuliu Hatieganu, Cluj - Napoca, 2007.

13.HU KS, HARRISON LB, CULLINEY B, etal. Cancer of the oropharynx. In: Harrison LB, Sessions RB, Hong WK, eds. Head and Neck Cancer: A Multidisciplinary Approach. 2nd ed. Philadelphia, Lippincott Williams \& Wilkins; 2004. p. 306-351.

14.J EREMIC $B$, SHIBAMOTO Y, MILICIC B, NIKOLIC N, DAGOVIC A, ALEKSANDROVIC J, VASKOVIC Z, TADIC L. Hyperfractionated radiation therapy with or without concurrent low-dose daily cisplatin in Articole de sinteza Jurnalul de Chirurgie, Iasi, 2010, Vol. 6, Nr. 1

15.LACCOURREYE O, MALINVAUD D, DELAS B, BONFILS P, CREVIERBUCHMAN L, MENAR M, et al. Early unilateral laryngeal paralysis after pulmonary resection with mediastinal dissection for cancer. Ann Thorac Surg. 2010; 90(4):1075-8.

16.BARLEAN, L., TATARCIUC, M., BALCOS, C., et al. Dentists Occupational Exposures to Chemicals During Hands Hygiene in the Dental Offices in lasi. Rev Chim. (Bucharest), 66, no. 10, 2015, p. 1696

17.LW BRADYET al.:Target Volume Delineation for Conformal and Intensity-Modulated Radiation Therapy (Medical Radiology / Radiation Oncology),Springer, 2014.

18.MENDELSOHN J, BASELGA J. Status of epidermal growth factor receptor antagonists in the biology and treatment of cancer. J Clin Oncol. 2003; 21 (14): 2787-2799.

19.FRANCU LL, HINGANU D, HINGANU MV. Anatomical evidence regarding sustentaculum facies. Rom J Morphol Embryol 2013; 54(3 Suppl): 757-761

20.MENDENHALL WM, AMDUR RJ, MORRIS CG, KIRWAN J , MALYAPA RS, VAYSBERG M, WERNING JW, MENDENHALL NP. Definitive radiotherapy for squamous cell carcinoma of the base of tongue. Am J Clin Oncol. 2006; 29 (1): 32-39.
21.MENDENHALL WM, MORRIS CG, AMDUR RJ, HINERMAN RW, MALYAPA RS, WERNING JW, LANSFORD CD, VILLARET DB. Definitive radiotherapy for squamous cell carcinoma of the base of tongue. Am J Clin Oncol. 2006; 29 (1): 32-39.

22.SCUTARIU, M.M., SURDU, A., MACOVEI, G., contributions to recognition of some particularities of the lingual mucosa conditions. Rev Med Chir Soc Med Nat lasi, 119, no.4, 2015, p. 1147-1152

23.NG SH, YEN TC, CHANG JT, CHAN SC, KO SF, WANG HM, LEE LY, KANG CJ, WONG AM, LIAO CT. Prospective study of [18F] fluorodeoxyglucose positron emission tomography and computed tomography and magnetic resonance imaging in oral cavity squamous cell carcinoma with palpably negative neck. J Clin Oncol. 2006; 24(27): 4371-4376.

24.NGUYEN NP, MOLTZCC, FRANK C, VOS P, SMITH HJ, KARLSSON U, et al. Evolution of chronic dysphagia following treatment for head and neck cancer. Oral Oncol. 2006; 42(4):374-80.

25.***Perez and Brady's Principles and Practice of Radiation Oncology, 5th Ed, Lippincott Williams \& Wilkins, 2008.

26.SEMRAU R, MUELLER RP, STUETZER H, STAAR S, SCHROEDER U, GUNTINAS-LICHIUS O, KOCHER M, EICH HT, DIETZ A, FLENTJE M, RUDAT V, VOLLING P, SCHROEDER M, ECKEL HE. Efficacy of intensified hyperfractionated and accelerated radiotherapy and concurrent chemotherapy with carboplatin and 5-fluorouracil: updated results of a randomized multicentric trial in advanced head-and-neck cancer. Int J Radiat Oncol Biol Phys. 2006; 64 (5): 1308-1316

27.HINGANU MV, HINGANU D, FRANCU LL. Rom J Morphol Embryol 2013, 54(3): 561-565

28. EISBRUCH A, LYDEN T, BRADFORD CR, DAWSON LA, HAXER MJ, MILLER AE, et al. Objective assessment of swallowing dysfunction and aspiration after radiation concurrent with chemotherapy for headand-neck cancer. Int J Radiat Oncol Biol Phys. 2002; 53(1):23-8.

29.SENDEROWICZ AM. Novel direct and indirect cyclin-dependent kinase modulators for the prevention and treatment of human neoplasms. Cancer Chemother Pharmacol. 2003; 52 (suppl 1): S61-73. 30.TREMMEL SC, GOTTE K, POPP S, WEBER S, HÖRMANN K, BARTRAM $\mathrm{CR}$, J AUCH A. Intratumoral genomic heterogeneity in advanced head and neck cancer detected by comparative genomic hybridization. Cancer Genet Cytogenet. 2003; 144 (2): 165-174.

31.VALENTIN IOAN CERNEA: Elemente de radiobiologie, Ed.Medicala Univ. Iuliu Hatiegnu, ClujNapoca, 2003.

32.VAN DER MOLEN L, VAN ROSSUM MA, ACKERSTAFF AH, SMEELE LE, RASCH CRN, HILGERSFJ M. Pretreatment organ function in patients with advanced head and neck cancer: clinical outcome measures and patients' views. BMC Ear Nose Throat Disord. 2009; 9:10.

33.**Walter and Miller's Textbook of Radiotherapy: Radiation Physics, Therapy and Oncology, 7th Ed, Elsevier, 2012.

Manuscript received: 16.09 .2018 